\title{
Physical exercise, gut, gut microbiota, and atherosclerotic cardiovascular diseases
}

\author{
Jingyuan Chen, Yuan Guo, Yajun Gui and Danyan Xu*
}

\begin{abstract}
Arteriosclerotic cardiovascular diseases (ASCVDs) are the leading cause of morbidity and mortality worldwide and its risk can be independently decreased by regular physical activity. Recently, ASCVD and its risk factors were found to be impacted by the gut microbiota through its diversity, distribution and metabolites. Meanwhile, several experiments demonstrated the relationship between physical exercise and diversity, distribution, metabolite of the gut microbiota as well as its functions on the lipid metabolism and chronic systematic inflammation. In this review, we summarize the current knowledge on the effects of physical exercise on ASCVD through modulation of the gut microbiota and intestinal function.
\end{abstract}

Keywords: Atherosclerosis, Physical exericise, Gut microbiota

\section{Background}

Cardiovascular diseases (CVDs) are the leading cause of morbidity and mortality worldwide [1]. Arteriosclerotic CVD (ASCVD) manifests as chronic ischemia in the affected organs over time or as acute symptoms such as myocardial infarction and ischemic stroke as a consequence of plaque destabilization or thrombus formation [2, 3].

Physical exercises could independently decrease the risk of ASCVD and also has a positive intensity-related impact on other cardiovascular risk factors, such as hyperlipidemia, hypertension, abdominal obesity, diabetes, and psychosocial factors. In addition, there is a positive correlation between exercise intensity and protective effects against ASCVD. Most authorities recommend higher-intensity aerobic exercise and resistance training to prevent and treat CVDs $[4,5]$.

Although physical exercise had been commended by lots of guidelines and expert consensus for its prevention and protection effects on ASCVD, its underline mechanisms were still not well understood. Several beneficial effects that acted on ASCVD had been found. First, the increased flow-mediated shear stress on the artery walls during exercise improves endothelial function. Second, aerobic exercise training is associated with reduced

* Correspondence: xudanyan01@126.com

Department of Cardiovascular Medicine, The Second Xiangya Hospital, Central South University, Changsha, Hunan 410011, China serum C-reactive protein levels. Furthermore, endurance exercise decreases blood pressure and serum triglyceride (TG) levels and improves high-density lipoprotein cholesterol levels (HDL-C), insulin sensitivity, and glucose homeostasis. Endurance exercise training also has potential anti-ischemic effects and increases coronary flow by augmenting capillary density and blood flow area [6].

Recently, ASCVD were found to be impacted by the gut microbiota through its diversity, distribution and metabolites. There were also some relations between gut microbiota, gut inflammation and ASCVD. Meanwhile, several experiments demonstrated the relationship between physical exercise and gut microbiota, and its influences on ASCVD risk factors such as the lipid metabolism and chronic systematic inflammation. In this review, we summarize the current knowledge on the effects of physical exercise on ASCVD through modulation of the gut microbiota and intestinal function.

\section{Gut microbiota and ASCVD}

Species, distribution and diversity of gut microbiota and ASCVD

Gut microbiota is the general term for bacterial microorganisms in the human digestive tract. The variety of microbes colonizing the human gut is almost 10 times that of the total cells in a human, and the genetic materials are more than 150-fold that of humans [7]. Classified by phyla, the gut microbiota mainly comprises Firmicutes 
and Bacteroides, which account for $80 \%-90 \%$ of all gut microbes, followed by Actinobacteria and Proteobacteria. Among these phyla, Firmicutes mainly includes Ruminococcus, Clostridium, Lactobacillus, Eubacterium, Faecalibacterium, and Roseburia, while Bacteroides mainly comprises Prevotella and Xylanibacter [8].

Researchers who screened the human gut microbiota composition based on the difference in bacteria gene discrepancy according to microorganism metagenome found that there are three types of human gut microbiota rather than a simple random assortment $[9,10]$. Accordingly, a new typing method was developed that stratifies gut microbiota into three enterotypes as determined by the abundance of key bacterial genera, namely, type 1 (mainly Bacteroides), type 2 (mainly Prevotella), and type 3 (mainly Ruminococcus, and smaller proportions of Bacteroides, Roseburia, and Blautia). Moreover, enterotypes are not related with age, sex, weight, or race, but with eating habits and means of energy utilization and vitamin synthesis. Relevant research on atherosclerosis and gut microbes has shown that patients with atherosclerosis are mainly enterotype 3 , with a minority of enterotype 1 [10].

In the following studies they found the atherosclerotic plaque area in female rats was positively correlated with Clostridiales (Firmicutes), Ruminococcus (Firmicutes,), and Lachnospiraceae (Firmicutes), and was negatively correlated with the S24-7 family of Bacterioidetes, which is similar to human enterotype research findings [11].

Intensive study of bacterial genera and families has proven that some rare genera or families are associated with ASCVD. A method based on the gut metagenome showed that the proportion of the genus Collinsella is increased in sympathetic atherosclerotic patients, while the proportions of Roseburia and Eubacteriumare greater in healthy individuals [10].

\section{Metabolites of gut microbiota and ASCVD Short chain fatty acid (SCFA) and ASCVD}

Short-chain fatty acids (SCFAs) are the major end products from the microbial degradation of carbohydrates and protein in the gut. The majority of SCFAs are absorbed from the gut and metabolized in various body tissues, contributing to some important physiological processes, especially effects daily energy requirements [12, 13].

Through the absorption and metabolism of SCFA, the host is able to obtain energy from foodstuffs that are not fully digested. SCFAs have numerous effects throughout the body, such as affecting epithelial cell transport and metabolism, growth and differentiation, and controlling lipid and carbohydrates metabolite in hepatocytes and providing energy sources [14]. For instance, propionates could reduce the cytokine-induced expression of cytokine induced adhesion molecules such as vascular cell adhesion molecule 1 (VCAM-1) and intercellular adhesion molecule 1 (ICAM-1) in endothelial cells by inhibiting nuclear factor-k $\mathrm{B}(\mathrm{NF}-\mathrm{\kappa} \mathrm{B})[15,16]$, lowers blood glucose and cholesterol, alter lipid metabolism [17], inhibit cholesterol synthesis in hepatocytes [18], which are all pathogenesis and risk factors of ASCVD.

\section{Trimethylamine $\mathrm{N}$-oxide (TMAO) and ASCVD}

Other than the abovementioned effects, the gut microbiota participate in the pathology of ASCVD through the metabolic product trimethylamine (TMA). In the setting of specific dietary nutrients characterized by TMA (e.g., choline, phosphatidylcholine, carnitine), the gut microbiota participate in the formation of the proatherogenic compound TMAO.

An accumulating amount of evidence suggests that, in humans, elevated concentrations of plasma TMAO are a marker of increased cardiovascular risk. Tang et al. [19] enrolled 4007 adults undergoing elective diagnostic cardiac catheterization to determine their fasting serum TMAO levels. Participants who had major adverse cardiovascular events had higher baseline levels of TMAO [20]. Compared with participants in the lowest quartile, those in the highest quartile had significantly increased risk of adverse cardiovascular events, indicating that TMAO remained a significant predictor of cardiovascular events risk [21].

Wang et al. first found that TMAO potentially promotes atherosclerosis by enhancing foam cell formation and decreasing reverse cholesterol transport (RCT) [22]. Subsequently, they screened a structural analog of choline, 3,3-dimethyl-1-butanol (DMB), which non-lethally inhibited TMA formation and decreased foam cell and atherosclerosis [11].

A detailed mechanism in vitro confirmed the mechanistic role of TMAO on foam cell formation through the upregulation of scavenger receptor A1 (SR-A1), ATP-binding cassette transporter A1 (ABCA1) and CD36 [22, 23]. However, at high baseline TMAO levels $(>0.05 \mathrm{ppm})$, the decrease in TMAO levels is associated with reduced aortic lesion area. Furthermore, TMAO and aortic lesion area in apolipoprotein E-null (apoE-/-) mice expressing human cholesteryl ester transfer protein (CETP) were not related. These results demonstrate that TMAO does not affect foam cell formation or endothelial cell dysfunction, the two first steps in atherosclerotic disease progression [24]. The discrepancies between these studies may be attributed to differences in diet composition, intervention drug dosage, and the sex and species of the experimental mice.

In patients with ASCVD, increased TMAO levels are associated with myocardial infarction, stroke, and allcause mortality, mainly because TMAO enhances 
platelet aggregation and thrombosis. The most recent research shows that TMAO promotes platelet hyperresponsiveness by enhancing the inositol-1,4,5-trisphosphate (IP3) signaling pathways and activating calcium ion $(\mathrm{Ca} 2+)$ release from intracellular $\mathrm{Ca} 2+$ stores [25].

\section{Gut microbiota and risk factors of ASCVD Gut microbiota and lipid metabolism}

Bacteroidetes is more common and Firmicutes is less ubiquitous in obese people than in lean people [26]. In addition, germ-free mice have lower fatty acid oxidization and decreased lipolysis [27, 28]. Metabolomic research that compared the blood lipid profiles between germ-free mice and typical breeding mice confirmed this conclusion, finding lower serum TG levels in germ-free mice, which was in accordance with the increased TG clearance [29].

Alterations in the intestinal microbiota, especially lactic acid bacteria (LAB), have yielded important modifications to lipid metabolism in animals [30-32] and humans [33]. Some yeast species can remove cholesterol [34], besides, Bifidobacteria decreases cholesterol levels by assimilation and precipitation [35], and is associated with serum HDL-C levels [36]. Furthermore, many experiments have shown a relationship between Erysipelotrichi and host lipid metabolism [36, 37]. In addition, gut microbial modification by antibiotic or probiotics use ameliorates dyslipidemia [38].

Research in vitro and in vivo has clarified the detailed mechanisms of the cholesterol-lowering effects of the gut microbiota, such as decreased gut assimilation, inhibition of the connection between cholesterol and the cell surface $[39,40]$, influencing the production of shortchain fatty acids [41], and accelerated bile acid and catalytic enzyme deconjugation [42, 43].

\section{Gut microbiota, endotoxins, and chronic systematic inflammation}

Gram-negative bacteria colonization leads to abundant endotoxins, especially LPS, in human and animal gut lumina. Several studies have reported low levels of serum LPS in humans, demonstrating that LPS is absorbed at a slow rate from the gastrointestinal lumen [44]. One major means of LPS absorption is infiltration of the tight junctions of the intestinal epithelium.

Decreasing tight junction protein levels augments LPS permeation, causing chronic inflammation such as visceral fat inflammation and macrophage infiltration $[44,45]$, which are risk factors of ASCVD [46].

Endotoxin levels are increased in obese rats and are accompanied by decreased intestinal endothelial zonula occludens-1 (ZO-1) and occludin levels [47]. The levels of serum endotoxins (especially LPS), proinflammatory cytokines, and hepatic inflammation in mice fed a HFD were decreased by broad-spectrum antibiotics, which altered the gut microbiota. These effects are associated with increased tight junction protein levels and decreased intestinal permeability [45]. Moreover, probiotics such as Lactobacillus improved the expression of tight junction proteins and ameliorated the absorption of LPS and its proinflammatory effects by improving the gut innate immune response [48]. Human Prevotella histicola reduces intestinal permeability and inflammation by upregulating the expression of enzymes that produce antimicrobial peptides and the expression of the tight junction proteins ZO-1 and occludin [49].

Among different inflammatory pathways, innate immunity, and particularly toll-like receptor (TLR)-activated pathways, have played an important role in the pathological process. TLR2 and TLR4 are the main receptors of LPS [50, 51], and TLR5 is a specific receptor of flagellin [52]. Gene mutation and gene knockout in TLR2 or TLR4 decrease TLR4 signaling and ameliorate atherosclerosis. Twelve-week treatment with broadspectrum antibiotics reduces intestinal microbiota diversity and inhibits TLR4 signaling [53]. TLR2 and TLR4 participate in tight junction protein regulation $[44,53,54]$. Gut microbiota dysbiosis also increases the levels of endotoxin and flagellin released by gramnegative bacteria, combining with TLR5 and contributing to intestinal endothelial inflammation and injury. Moreover, this disruption of the intestinal environment is modestly related with damage to the tight junction proteins claudins (CLDN) and occludins [55].

\section{Physical exercise and gut microbiota}

The modern lifestyle, such as diet and exercise, influences gut microbiota composition and the health of the host to an extent. Compared with research on diet, research on the relationship between physical exercise and gut microbiota is less well developed.

\section{Physical exercise, microbial distribution, and diversity}

There are several studies demonstrate that physical exercise increases microbiota diversity and modulates its distribution (Table 1). Bacterial diversity is decreased in sedentary elderly individuals as compared with elderly individuals who have physical exercise. The gut microbiota of professional rugby players were more diverse than that of non-athlete healthy subjects [56]. Santacruz [57] compared changes in the gut microbial distribution of obese adults who had moderate to severe aerobic exercise for 10 weeks and found increased Bacteroidetes and decreased Firmicutes. These studies suggest that exercise can alter microbiota diversity and distribution in humans.

Experiments in rats have also yielded the same result, in which there was an effect on microbial distribution between HFD and voluntary exercise. In that study, 
Table 1 Studies about exercise and gut microbiota

\begin{tabular}{|c|c|c|c|c|}
\hline Model & Exercise & Changes of microbial groups or SCFA & Position & Reference \\
\hline $\begin{array}{l}\text { diet-induced obesity } \\
\text { C57 BL/6 mice }\end{array}$ & $\begin{array}{l}\text { high-intensity interval training } \\
\text { (HIIT) for } 6 \text { weeks }\end{array}$ & $\begin{array}{l}\uparrow \text { Bacteroidetes/Firmicutes } \\
\uparrow F e c a l \text { microbiota genetic capacity }\end{array}$ & $\begin{array}{l}\text { distal gut } \\
\text { feces }\end{array}$ & [59] \\
\hline Normal diet SD rats & $\begin{array}{l}\text { voluntary access to exercise } \\
\text { (i.e., wheel running) }\end{array}$ & $\begin{array}{l}\uparrow \text { Bacteroidetes } \\
\downarrow \text { Firmicutes } \uparrow \text { Lactobacillus, Bifodobacterim } \\
\uparrow \text { Blautia Coccoides Eubacterium rectale } \\
\downarrow \text { Clostridium Enterococcus }\end{array}$ & feces & [70] \\
\hline 6w Male Wistar rats & voluntary running exercise & $\begin{array}{l}\text { } \text { butyrate } \\
\uparrow p h y l u m \text { of Firmicutes (SM7/11, T2-87) }\end{array}$ & colon & {$[62]$} \\
\hline Rugby players & rugby & $\begin{array}{l}\uparrow \text { microbial diversity } \\
\uparrow A k \text { Akermansia } \\
\uparrow \text { Firmicutes in athletes } \\
\downarrow \text { Bacteroidetes }\end{array}$ & feces & [71] \\
\hline Diabetic Mice(db/db) & low-intensity treadmill running & $\begin{array}{l}\uparrow \text { Firmicutes } \\
\downarrow \text { Bacteroides/Prevotella }\end{array}$ & $\begin{array}{l}\text { cecal } \\
\text { feces }\end{array}$ & {$[60]$} \\
\hline
\end{tabular}

exercise increased the percentage of Bacteroidetes and decreased the percentage of Firmicutes regardless of diet; moreover, the ratio of Bacteroidetes to Firmicutes correlated inversely with the amount of exercise performed [58]. In a recent experiment, Emmanuel et al. [59] found that high-intensity interval training increased the Bacteroidetes to Firmicutes ratio of the distal gut and fecal microbiota during diet-induced obesity.

Firmicutes and Bacteroidetes are the most abundant microorganisms at phylum level and account for more than $90 \%$ of the total microbiota. Moreover, intestinal flora are complicated, spurring intensive research on particular populations but not on the Firmicutes to Bacteroidetes ratio.

Research on the effect of physical exercise on diabetic and normal mice has shown that physical exercise correlates with decreased proportions of Bacteroides/Prevotella spp. and Methanobrevibacter spp. and increased proportions of Lactobacillus spp. [48].

The most recent study comparing the effects of physical exercise on different diets showed that exercise altered the gut microbiota distribution in both HFD and normal diet, and the unique genera associated with physical exercise are Faecalibacterium prausnitzii (Firmicutes), Clostridium spp. (Firmicutes), and Allobaculum spp. (Mycoplasmataceae) [60]. Moreover, the proportions of Allobaculum spp. and Clostridiales were increased after exercise (either HFD or normal diet) as compared with sedentary groups (either HFD or normal diet), and F. prausnitzii was only present in the exercise groups regardless of animal species [61], which is consistent with previous study findings.

\section{Physical exercise and SCFA}

There are also a few studies proved that exercises could promote formation of SCFA. In animal models, it has been observed that running exercise increases fecal butyrate levels, and this change is associated with changes in butyrate producer bacteria groups [62]. Voluntarily wheel exercise was also found to increase cecal acetate and propionate. Therefore, increased SCFAs production induced by microbiota profile changes could be one of the mechanisms by which physical exercise promotes health, since SCFA butyrate has the ability to inhibit histone deacetylases, and subsequently it has an impact on gene regulation, immune modulation, intestinal barrier regulation, oxidative stress reduction, diarrhea control, visceral sensitivity, and intestinal motility modulation [63], which all participate in the modulation of ASCVD. Moreover, SCFAs catabolited by the microbiota were found to activate AMPK pathway that controls the activity of various factors implicated in the regulation of cholesterol levels and metabolism of lipids and glucose in the muscle [64].

\section{Physical exercise influences ASCVD risk factors through intestinal functions}

There are several evidences that habitual physical activity is anti-inflammatory and protective against developing chronic inflammatory diseases. Recent studies have related intestinal dysbiosis to pathogenic microbes and there are also results indicates increased inflammatory disease susceptibility [65]. There were some animal and human researches demonstrate that exercise may have a beneficial role in preventing and ameliorating chronic inflammatory diseases by having an effect on gut immune function and microbiome characteristics. These researches showed that different forms of exercise training differentially impact the severity of intestinal inflammation during an inflammatory circumstance and could be linked to gut immune cell homeostasis and microbiota-immune interactions. 


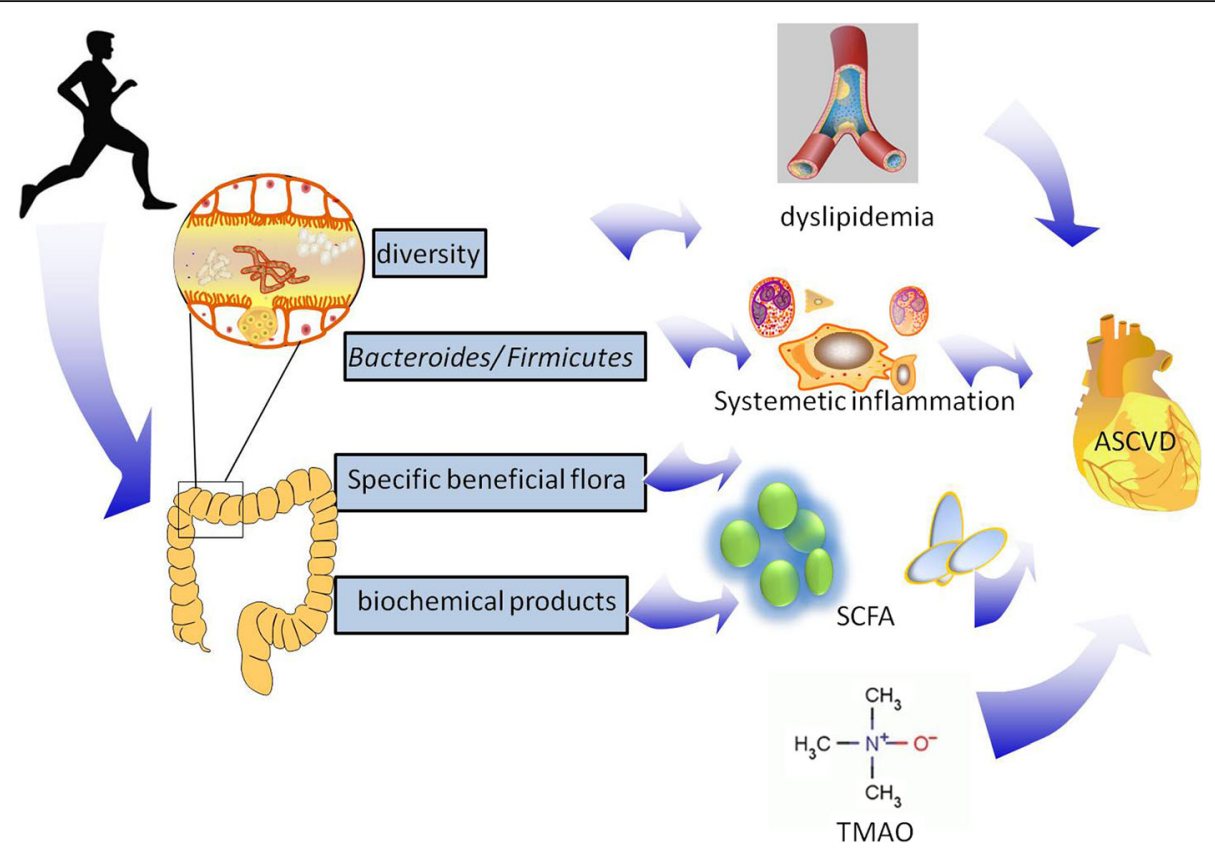

Fig. 1 Schematic summary of effects that exercise had on ASCVD

Research on the field of physical exercise and intestinal permeability mostly shows that strenuous exercise increases gut permeability induced by intestinal ischemia. This is the cause of abdominal discomfort and diarrhea in athletes while they are competing [66, 67]. However, these findings may not be the only connection between exercise and gut permeability. A decrease of about only $50 \%$ in the intestinal blood stream causes intestinal permeability deterioration. Moreover, the intestinal blood stream of foxhounds did not decrease further after 8-12 weeks of exercise training [68]. These findings indicate that the increased gut permeability induced by intestinal ischemia is associated with the intensity, duration, and adaptability of exercise.

The mRNA levels of CLDN1 and ZO-1, major components of the tight junction, were increased in rat ileum after intermediate endurance swimming for $1 \mathrm{~h}$ a day, indicating that endurance exercise may decrease gut permeability [69]. However, other studies have reported conflicting results. For example, both the elements and the proportions of tight junction proteins differ between different running exercises. Nevertheless, the conflicting results indicate a relationship between physical exercise, gut permeability, and the tight junction. It was also affirmed that exercise reduces LPS-induced systemic inflammation. Moreover, many studies have proven that physical exercise suppresses chronic inflammatory diseases by influencing the gut microbiota. Overall, the effects of exercise type and exercise level, and the underlying mechanism, should be investigated intensively.

\section{Conclusions and prospects}

Although no direct evidence supports the premise that physical exercise prevents ASCVD by modifying the gut microbiota and by alleviating systematic inflammation, many studies have confirmed this hypothesis. Some intestinal floras are specifically related with exercise and ASCVD, and may contain species that could ameliorate atherosclerosis by exercise Fig. 1.

As we gain a deeper understanding of the specific relationships between physical exercise, gut microbiota and ASCVD, we expose potential therapeutic ways. However, in the field of CVDs, the gut microbiota is a newly emerging topic and has raised many questions. For example, how does exercise-induced change in the precise gut microbiota composition decrease TMA or TMAO production? What strength grade, aerobic exercise, or resistive exercise should patients undertake to achieve the best therapeutic effect? Should we undertake higher intensity exercise, low-intensity activity, or endurance training? What is the most suitable time to exercise? These questions all warrant further research.

\footnotetext{
Abbreviations

ABCA1: ATP-binding cassette transporter A1; ASCVD: Arteriosclerotic cardiovascular disease; CETP: Cholesteryl ester transfer protein;

CLDN: Claudin; CVD: Cardiovascular diseases; DMB: 3,3-dimethyl-1-butanol; dsRNA: Double-stranded RNA; HDL-C: High-density lipoprotein cholesterol; HFD: High-fat diet; ICAM-1: Intercellular adhesion molecule 1; IFN-

$\beta$ : Interferon- $\beta$; IP3: Inositol-1,4,5-trisphosphate; LAB: Lactic acid bacteria; LPS: Lipopolysaccharide; NF-KB: Nuclear factor-K B; RCT: Reverse cholesterol transport; SCFA: Short chain fatty acid; SR-A1: Scavenger receptor A1; TG: Triglyceride; TLR: Toll-like receptor; TMA: Trimethylamine;

TMAO: Trimethylamine N-oxide; VCAM-1: Vascular cell adhesion molecule 1
} 


\section{Acknowledgements}

Not applicable.

\section{Funding}

This work was supported by the grant from the National Natural Science Foundation of China (No.81372117, 81672264).

\section{Availability of data and materials}

Data sharing not applicable to this article as o datasets were generated or analysed during the current study.

\section{Authors' contributions}

JY Chen came up with writing this review and drafted the manuscript. DY $\mathrm{Xu}, \mathrm{Y}$ Guo and YJ Gui helped to draft the manuscript. Above authors read and approved the final manuscript.

\section{Ethics approval and consent to participate}

Not applicable.

\section{Consent for publication}

Not applicable.

\section{Competing interests}

The authors declare that they have no competing interests.

\section{Publisher's Note}

Springer Nature remains neutral with regard to jurisdictional claims in published maps and institutional affiliations.

Received: 16 September 2017 Accepted: 27 December 2017

Published online: 22 January 2018

\section{Reference}

1. Mozaffarian D, Benjamin EJ, Go AS, Arnett DK, Blaha MJ, Cushman M, de Ferranti S, Despres JP, Fullerton HJ, Howard VJ, et al. Heart disease and stroke statistics-2015 update: a report from the American Heart Association. Circulation. 2015;131:e29-322.

2. Shapiro MD, Fazio S. From Lipids to Inflammation: New Approaches to Reducing Atherosclerotic Risk. Circ Res. 2016;118:732-49.

3. Wang SH, Yuan SG, Peng DQ, Zhao SP. HDL and ApoA-I inhibit antigen presentation-mediated T cell activation by disrupting lipid rafts in antigen presenting cells. Atherosclerosis. 2012;225:105-14.

4. Thompson PD, Franklin BA, Balady GJ, Blair SN, Corrado D, Estes NA 3rd, Fulton JE, Gordon NF, Haskell WL, Link MS, et al. Exercise and acute cardiovascular events placing the risks into perspective: a scientific statement from the American Heart Association Council on Nutrition, Physical Activity, and Metabolism and the Council on Clinical Cardiology. Circulation. 2007;115:2358-68.

5. Price KJ, Gordon BA, Bird SR, Benson AC. A review of guidelines for cardiac rehabilitation exercise programmes: Is there an international consensus? Eur J Prev Cardiol. 2016;

6. Alpers $\mathrm{DH}$. Absorption and blood/cellular transport of folate and cobalamin: Pharmacokinetic and physiological considerations. Biochimie. 2016;126:52-6.

7. Qin J, Li R, Raes J, Arumugam M, Burgdorf KS, Manichanh C, Nielsen T, Pons $\mathrm{N}$, Levenez $\mathrm{F}$, Yamada $\mathrm{T}$, et al. A human gut microbial gene catalogue established by metagenomic sequencing. Nature. 2010;464:59-65.

8. Eckburg PB, Bik EM, Bernstein CN, Purdom E, Dethlefsen L, Sargent M, Gill $\mathrm{SR}$, Nelson KE, Relman DA. Diversity of the human intestinal microbial flora. Science. 2005;308:1635-8.

9. Arumugam M, Raes J, Pelletier E, Le Paslier D, Yamada T, Mende DR, Fernandes GR, Tap J, Bruls T, Batto J-M. Enterotypes of the human gut microbiome. nature. 2011;473:174-80

10. Houghton D, Stewart CJ, Day CP, Trenell M. Gut Microbiota and Lifestyle Interventions in NAFLD. International journal of molecular sciences. 2016;17:447.

11. Wang Z, Roberts AB, Buffa JA, Levison BS, Zhu W, Org E, Gu X, Huang Y, Zamanian-Daryoush M, Culley MK, et al. Non-lethal Inhibition of Gut Microbial Trimethylamine Production for the Treatment of Atherosclerosis. Cell. 2015;163:1585-95.
12. Cummings $\mathrm{JH}$, Macfarlane GT. The control and consequences of bacterial fermentation in the human colon. The Journal of applied bacteriology. 1991;70:443-59.

13. Cheng J, Song J, He X, Zhang M, Hu S, Zhang S, Yu Q, Yang P, Xiong F, Wang DW, et al. Loss of Mbd2 Protects Mice Against High-Fat Diet-Induced Obesity and Insulin Resistance by Regulating the Homeostasis of Energy Storage and Expenditure. Diabetes. 2016;65:3384-95.

14. Macfarlane GT, Macfarlane S, et al. J AOAC Int. 2012;95:50-60.

15. Zhan JK, Tan P, Wang YJ, Wang Y, He JY, Tang ZY, Huang W, Liu YS Exenatide can inhibit calcification of human VSMCs through the NF-kappaB/ RANKL signaling pathway. Cardiovasc Diabetol. 2014;13:153.

16. Zapolska-Downar D, Naruszewicz M. Propionate reduces the cytokineinduced VCAM-1 and ICAM-1 expression by inhibiting nuclear factor-kappa B (NF-kappaB) activation. J Physiol Pharmacol. 2009;60:123-31.

17. Todesco T, Rao AV, Bosello O, Jenkins DJ. Propionate lowers blood glucose and alters lipid metabolism in healthy subjects. Am J Clin Nutr. 1991;54:860-5.

18. Illman RJ, Topping DL, GH MI, Trimble RP, Storer GB, Taylor MN, Cheng BQ. Hypocholesterolaemic effects of dietary propionate: studies in whole animals and perfused rat liver. Ann Nutr Metab. 1988;32:95-107.

19. Tang WH, Wang Z, Levison BS, Koeth RA, Britt EB, Fu X, Wu Y, Hazen SL. Intestinal microbial metabolism of phosphatidylcholine and cardiovascular risk. N Engl J Med. 2013;368:1575-84.

20. Karlsson H, Mortstedt $\mathrm{H}$, Lindqvist $\mathrm{H}$, Tagesson C, Lindahl M. Protein profiling of low-density lipoprotein from obese subjects. Proteomics Clin Appl. 2009;3:663-71.

21. Yin J, Liao SX, He Y, Wang S, Xia GH, Liu FT, Zhu JJ, You C, Chen Q, Zhou L, et al. Dysbiosis of Gut Microbiota With Reduced Trimethylamine-N-Oxide Level in Patients With Large-Artery Atherosclerotic Stroke or Transient Ischemic Attack. Journal of the American Heart Association. 2015;4

22. Wang Z, Klipfell E, Bennett BJ, Koeth R, Levison BS, Dugar B, Feldstein AE, Britt EB, Fu X, Chung YM, et al. Gut flora metabolism of phosphatidylcholine promotes cardiovascular disease. Nature. 2011;472:57-63.

23. Mohammadi A, Najar AG, Yaghoobi MM, Jahani Y, Vahabzadeh Z Trimethylamine-N-Oxide Treatment Induces Changes in the ATP-Binding Cassette Transporter A1 and Scavenger Receptor A1 in Murine Macrophage J774A.1 cells. Inflammation. 2016;39:393-404

24. Collins HL, Drazul-Schrader D, Sulpizio AC, Koster PD, Williamson Y, Adelman SJ, Owen K, Sanli T, Bellamine A. L-Carnitine intake and high trimethylamine $\mathrm{N}$-oxide plasma levels correlate with low aortic lesions in ApoE(-/-) transgenic mice expressing CETP. Atherosclerosis. 2016;244:29-37.

25. Zhu W, Gregory JC, Org E, Buffa JA, Gupta N, Wang Z, Li L, Fu X, Wu Y, Mehrabian M, et al. Gut Microbial Metabolite TMAO Enhances Platelet Hyperreactivity and Thrombosis Risk. Cell. 2016;165:111-24.

26. Ley RE, Turnbaugh PJ, Klein S, Gordon JI. Microbial ecology: human gut microbes associated with obesity. Nature. 2006:444:1022-3.

27. Backhed F, Ding H, Wang T, Hooper LV, Koh GY, Nagy A, Semenkovich CF, Gordon J. The gut microbiota as an environmental factor that regulates fat storage. Proc Natl Acad Sci U S A. 2004;101:15718-23.

28. Backhed F, Manchester JK, Semenkovich CF, Gordon Jl. Mechanisms underlying the resistance to diet-induced obesity in germ-free mice. Proc Natl Acad Sci U S A. 2007;104:979-84.

29. Velagapudi VR, Hezaveh R, Reigstad CS, Gopalacharyulu P, Yetukuri L, Islam S, Felin J, Perkins R, Borén J, Orešič M. The gut microbiota modulates host energy and lipid metabolism in mice. Journal of lipid research. 2010;51:1101-12.

30. Lee DK, Jang S, Baek EH, Kim MJ, Lee KS, Shin HS, Chung MJ, Kim JE, Lee $\mathrm{KO}, \mathrm{Ha}$ NJ. Lactic acid bacteria affect serum cholesterol levels, harmful fecal enzyme activity, and fecal water content. Lipids Health Dis. 2009;8:21.

31. Liong MT, Dunshea FR, Shah NP. Effects of a synbiotic containing Lactobacillus acidophilus ATCC 4962 on plasma lipid profiles and morphology of erythrocytes in hypercholesterolaemic pigs on high- and low-fat diets. Br J Nutr. 2007;98:736-44.

32. Xie N, Cui $Y$, Yin YN, Zhao X, Yang JW, Wang ZG, Fu N, Tang Y, Wang XH, Liu XW, et al. Effects of two Lactobacillus strains on lipid metabolism and intestinal microflora in rats fed a high-cholesterol diet. BMC Complement Altern Med. 2011;11:53

33. Guo Z, Liu XM, Zhang QX, Shen Z, Tian FW, Zhang H, Sun ZH, Zhang HP Chen $\mathrm{W}$. Influence of consumption of probiotics on the plasma lipid profile: a meta-analysis of randomised controlled trials. Nutr Metab Cardiovasc Dis. 2011;21:844-50. 
34. Madeeha IR, Ikram A, Imran M. A preliminary insight of correlation between human fecal microbial diversity and blood lipid profile. Int $J$ Food Sci Nutr. 2016:1-7.

35. Tahri K, Crociani J, Ballongue J, Schneider F. Effects of three strains of bifidobacteria on cholesterol. Lett Appl Microbiol. 1995;21:149-51.

36. Martinez I, Wallace G, Zhang C, Legge R, Benson AK, CarrTP MEN, Walter J. Diet-induced metabolic improvements in a hamster model of hypercholesterolemia are strongly linked to alterations of the gut microbiota. Appl Environ Microbiol. 2009;75:4175-84.

37. Zhang C, Zhang M, Wang S, Han R, Cao Y, Hua W, Mao Y, Zhang X, Pang $X$, Wei $C$, et al. Interactions between gut microbiota, host genetics and diet relevant to development of metabolic syndromes in mice. Isme j. 2010;4:232-41.

38. Asemi Z, Zare Z, Shakeri H, Sabihi SS, Esmaillzadeh A. Effect of multispecies probiotic supplements on metabolic profiles, hs-CRP, and oxidative stress in patients with type 2 diabetes. Ann Nutr Metab. 2013;63:1-9.

39. Lye HS, Rahmat-Ali GR, Liong MT. Mechanisms of cholesterol removal by lactobacilli under conditions that mimic the human gastrointestinal tract. International Dairy Journal. 2010;20:169-75.

40. Lye HS, Rusul G, Liong MT. Removal of cholesterol by lactobacilli via incorporation and conversion to coprostanol. J Dairy Sci. 2010;93:1383-92.

41. De Preter V, Vanhoutte T, Huys G, Swings J, De Vuyst L, Rutgeerts P, Verbeke K. Effects of Lactobacillus casei Shirota, Bifidobacterium breve, and oligofructose-enriched inulin on colonic nitrogen-protein metabolism in healthy humans. Am J Physiol Gastrointest Liver Physiol. 2007;292:G358-68.

42. Ishimwe N, Daliri EB, Lee BH, Fang F, Du G. The perspective on cholesterollowering mechanisms of probiotics. Mol Nutr Food Res. 2015;59:94-105.

43. Kumar M, Nagpal R, Kumar R, Hemalatha R, Verma V, Kumar A, Chakraborty C, Singh B, Marotta F, Jain S, Yadav H. Cholesterol-lowering probiotics as potential biotherapeutics for metabolic diseases. Exp Diabetes Res. 2012; 2012:902917.

44. Cani PD, Possemiers S, Van de Wiele T, Guiot Y, Everard A, Rottier O, Geurts L, Naslain D, Neyrinck A, Lambert DM. Changes in gut microbiota control inflammation in obese mice through a mechanism involving GLP-2-driven improvement of gut permeability. Gut. 2009;58:1091-103.

45. Cani PD, Bibiloni R, Knauf C, Waget A, Neyrinck AM, Delzenne NM, Burcelin R. Changes in gut microbiota control metabolic endotoxemia-induced inflammation in high-fat diet-induced obesity and diabetes in mice. Diabetes. 2008;57:1470-81.

46. Lam YY, Ha CW, Campbell CR, Mitchell AJ, Dinudom A, Oscarsson J, Cook DI, Hunt NH, Caterson ID, Holmes AJ, Storlien LH. Increased gut permeability and microbiota change associate with mesenteric fat inflammation and metabolic dysfunction in diet-induced obese mice. PLoS One. 2012;7:e34233.

47. Johnston DG, Corr SC. Toll-Like Receptor Signalling and the Control of Intestinal Barrier Function. Methods Mol Biol. 2016;1390:287-300.

48. Kim SH, Jeung W, Choi ID, JeongJW LDE, Huh CS, Kim GB, Hong SS, Shim JJ, Lee JL, et al. Lactic Acid Bacteria Improves Peyer's Patch Cell-Mediated Immunoglobulin A and Tight-Junction Expression in a Destructed Gut Microbial Environment. J Microbiol Biotechnol. 2016;26:1035-45.

49. Marietta EV, Murray JA, Luckey DH, Jeraldo PR, Lamba A, Patel R, Luthra HS, Mangalam A, Taneja V. Human Gut-Derived Prevotella histicola Suppresses Inflammatory Arthritis in Humanized Mice. Arthritis Rheumatol. 2016;

50. Du T, Zhou ZG, You S, Huang G, Lin J, Yang L, Li X, Zhou WD, Chao C. Modulation of monocyte hyperresponsiveness to TLR ligands by 1,25dihydroxy-vitamin D3 from LADA and T2DM. Diabetes Res Clin Pract. 2009; 83:208-14.

51. Chow JC, Young DW, Golenbock DT, Christ WJ, Gusovsky F. Toll-like receptor-4 mediates lipopolysaccharide-induced signal transduction. Journal of Biological Chemistry. 1999;274:10689-92.

52. Yoon SI, Kurnasov O, Natarajan V, Hong MS, Gudkov AV, Osterman AL, Wilson IA. Structural Basis of TLR5-Flagellin Recognition and Signaling. Science. 2012;335:859-64.

53. Anitha M, Vijay-Kumar M, Sitaraman SV, Gewirtz AT, Srinivasan S. Gut microbial products regulate murine gastrointestinal motility via Toll-like receptor 4 signaling. Gastroenterology. 2012;143:1006-1016.e1004.

54. Cario E, Gerken G, Podolsky DK. Toll-like receptor 2 controls mucosal inflammation by regulating epithelial barrier function. Gastroenterology. 2007:132:1359-74.

55. Chassaing B, Ley RE, Gewirtz AT. Intestinal Epithelial Cell Toll-like Receptor 5 Regulates the Intestinal Microbiota to Prevent Low-Grade Inflammation and Metabolic Syndrome in Mice. Gastroenterology. 2014;147:1363-+.
56. Mann CJ, Troussard AA, Yen FT, Hannouche N, Najib J, Fruchart JC, Lotteau $V$, Andre P, Bihain BE. Inhibitory effects of specific apolipoprotein C-III isoforms on the binding of triglyceride-rich lipoproteins to the lipolysisstimulated receptor. J Biol Chem. 1997;272:31348-54.

57. Santacruz A, Marcos A, Warnberg J, Marti A, Martin-Matillas M, Campoy C, Moreno LA, Veiga O, Redondo-Figuero C, Garagorri JM, et al. Interplay between weight loss and gut microbiota composition in overweight adolescents. Obesity (Silver Spring). 2009;17:1906-15.

58. Evans CC, KJ LP, Kwak JW, Stancukas MC, Laskowski S, Dougherty J, Moulton L, Glawe A, Wang Y, Leone $V$, et al. Exercise prevents weight gain and alters the gut microbiota in a mouse model of high fat diet-induced obesity. PLoS One. 2014;9:e92193.

59. Denou E, Marcinko K, Surette MG, Steinberg GR, Schertzer JD. High-intensity exercise training increases the diversity and metabolic capacity of the mouse distal gut microbiota during diet-induced obesity. American Journal of Physiology-Endocrinology and Metabolism. 2016;310:E982-93.

60. Lambert JE, Myslicki JP, Bomhof MR, Belke DD, Shearer J, Reimer RA. Exercise training modifies gut microbiota in normal and diabetic mice. Appl Physiol Nutr Metab. 2015:40:749-52.

61. Kang SS, Jeraldo PR, Kurti A, MEB M, Cook MD, Whitlock K, Goldenfeld N, Woods JA, White BA, Chia N. Diet and exercise orthogonally alter the gut microbiome and reveal independent associations with anxiety and cognition. Molecular neurodegeneration. 2014;9:1.

62. Matsumoto M, Inoue R, Tsukahara T, Ushida K, Chiji H, Matsubara N, Hara $\mathrm{H}$. Voluntary running exercise alters microbiota composition and increases n-butyrate concentration in the rat cecum. Biosci Biotechnol Biochem. 2008;72:572-6.

63. Leonel AJ, Alvarez-Leite J. Butyrate: implications for intestinal function. Curr Opin Clin Nutr Metab Care. 2012;15:474-9.

64. den Besten G, van Eunen K, Groen AK, Venema K, Reijngoud DJ, Bakker BM. The role of short-chain fatty acids in the interplay between diet, gut microbiota, and host energy metabolism. J Lipid Res. 2013;54:2325-40.

65. Chen HM, Liu XW, Sun RJ, Fang JY. A survey on the developmental intestinal microbiota research in China: The history, funding, and frontiers of gut bacteria. J Dig Dis. 2015;16:421-30.

66. Martin D. Physical activity benefits and risks on the gastrointestinal system. South Med J. 2011:104:831-7.

67. Moses FM. Exercise-associated intestinal ischemia. Curr Sports Med Rep. 2005;4:91-5

68. Musch TI, Haidet GC, Ordway GA, Longhurst JC, Mitchell JH. Training effects on regional blood flow response to maximal exercise in foxhounds. J Appl Physiol (1985). 1987;62:1724-32.

69. Teerapornpuntakit J, Dorkkam N, Wongdee K, Krishnamra N, Charoenphandhu N. Endurance swimming stimulates transepithelial calcium transport and alters the expression of genes related to calcium absorption in the intestine of rats. Am J Physiol Endocrinol Metab. 2009;296:E775-86.

70. Queipo-Ortuno MI, Seoane LM, Murri M, Pardo M, Gomez-Zumaquero JM, Cardona F, Casanueva F, Tinahones FJ. Gut microbiota composition in male rat models under different nutritional status and physical activity and its association with serum leptin and ghrelin levels. PLoS One. 2013;8:e65465.

71. Clarke SF, Murphy EF, O'Sullivan O, Lucey AJ, Humphreys M, Hogan A, Hayes P, O'Reilly M, Jeffery IB, Wood-Martin R, et al. Exercise and associated dietary extremes impact on gut microbial diversity. Gut. 2014;63:1913-20.

\section{Submit your next manuscript to BioMed Central and we will help you at every step:}

- We accept pre-submission inquiries

- Our selector tool helps you to find the most relevant journal

- We provide round the clock customer support

- Convenient online submission

- Thorough peer review

- Inclusion in PubMed and all major indexing services

- Maximum visibility for your research

Submit your manuscript at www.biomedcentral.com/submit 